\title{
Heat Treatment Effect on Mechanical Properties of 3D Printed Polymers
}

\author{
Eduardo de Avila ${ }^{1}$, Jaeseok Eo ${ }^{2}$, Jihye $\mathrm{Kim}^{1}$ and Namsoo P. Kim ${ }^{1,2, a}$ \\ ${ }^{1}$ Center for Printable Materials Certification (CPMC), The University of Texas at El Paso, El Paso, TX 79968, USA. \\ ${ }^{2}$ Metallurgical, Materials and Biomedical Engineering Department, The University of Texas at El Paso, El Paso, TX 79968, USA.
}

\begin{abstract}
PMMA, PC, and PEEK are thermoplastic polymers that possess favorable properties for biomedical applications. These polymers have been used in fields of maxillo-facial, orthopedic, intraocular surgery, and bio-implant, due to their excellent mechanical properties, osteoinductive potential, and antimicrobial capabilities. In this study, the effect of heat treatment on the mechanical properties of $3 D$ printed polymers was characterized. By modifying printing temperature and post heat treatment process, the mechanical properties were specifically tailored for different applications, correlating with the properties of the implants that are commonly made using molding processes.
\end{abstract}

\section{INTRODUCTION}

Mechanical properties of materials including elasticity, yield strength, ultimate tensile strength, flexural strength, and ductility are part of materials specifications, and these properties determine the duration, biocompatibility, regeneration of biomaterials when the implantation is applied. Materials scientists have studied various ways of modifying the intrinsic properties of materials, either by combining one or more materials to produce different types of alloys or composites or by subjecting them to specific processes, such as heat treating. Heat treatment of polymers is one of the most effective methods of modifying the mechanical properties and widening their applications.

Additive Manufacturing (AM) or 3D printing technology have been applied to a biomedical application for the invitro and in-vivo test using metal/polymer implantation materials. However, the materials and process itself has not been standardized so far and still has unknown factors [1]. 3D printed polymers or composite polymers for medical application need to be tested for printability, reliability, and reproducibility in the geometry required for tensile specimens according to ASTM D638 [2]. The uncertainties of 3D printing technology which come from the heat transformation, energy dissipation and cooling should be clarified. For the reliability test, the specimens were heat treated at various temperatures to measure the changes in mechanical properties. The heat treatment of polymer-based composites resulted in improvement of mechanical properties, including fatigue resistance, fracture toughness, tensile strength, wear resistance, and friction coefficient [3]. The flexural properties have been tested following ASTM 790 [4]. The friction tests in polymers have reported to be affected by various aspects such as real contact area, which is dependent on temperature and sliding velocity [5].

Velocity has a different effect on friction characteristics, depending on whether the test is conducted at low or high speeds. This is also applicable for the contact pressure or applied load [6]. In this study, we have attempted to compare the friction behavior of the polymers before and after heat treatment.

Thermoplastic polymers such as PMMA, Polycarbonate (PC), and Poly(aryl-ether-ether-ketone) (PEEK) have been used for the mechanical analysis.

PMMA is a non-degradable polyacrylate, the most commonly applied non-metallic implant material in orthopedics. Due to its excellent biocompatibility, hemocompatibility, and ease of manipulation, PMMA has been widely used in many medical devices, including blood pumps and dialyzers. It is an ideal candidate material for implantable ocular lenses and hard contact lenses by its optical properties [7].

Polycarbonate (PC) is one of the most popular engineering resins in the medical device market, offering an unusual combination of strength, rigidity, and toughness. It provides glass-like clarity that is critical for many medical devices [8]. It is a thoroughly tested plastic used today and has a safety track record of more

\footnotetext{
${ }^{\mathrm{a}}$ Corresponding author: nkim@utep.edu
} 
than 50 years. It is available in different grades that comply with biocompatibility testing standards[8].

Poly(aryl-ether-ether-ketone) (PEEK) belongs to a family of high-temperature thermoplastic polymers, consisting of an aromatic backbone molecular chain, interconnected by ketone and ether functional groups. PEEK has been applied as a biomaterial over a decade, and a half of the uses are successful in the clinical history of load sharing fusion applications in the spine [9][10].

Biomaterials, human-made or natural origin, are used to supplement, direct, or replace parts or functions of living tissues in the human body. Biomaterials perform in the body's internal environment, withstanding the $\mathrm{pH}$ of body fluids as well as stress and compression forces, which may vary up to 10 times the body weight, as when jumping $(9,000 \mathrm{~N})[11]$.

In general, metals or ceramics are used for hard tissue applications, and polymers are used for soft tissue applications [12]. A wide number of polymers are used in various biomedical applications; however, most of the plastic composites are too flexible or too weak to meet the demands of a particular applications. One of the attempts to improve the mechanical strength and electrical conductivity of $3 \mathrm{D}$ printed structures was implemented by adding nanoparticles to polymers, metals, and ceramics matrix. [13-15].

It is reported the tensile strength of the biopolymer composite could be increased by $40 \%$, due to the increase of the interface area, packing factors and internal energy. [16] The feasibility of the printability and modification of specific properties by heat treatment is explored to evaluate the practicability of polymer, polymercomposites and dispensing powders in non-traditional applications [17-20]. In a case of 3D printing with polymer or composite materials, effects of the apparent density changes in various printing techniques, including theoretical studies on electrical conductivity as well as mechanical strength were discussed, and standardization of the mechanical strength studies have also been reported. [21]. The Hagen-Poiseuille (HP) equation was applied to find the constant volume flow rate and the variation in the amount of discharged fluid for nonNewtonian material and applied to 3D printed liquid drugs. A procedure to control the constant volume flow has been formulated into 3D-printed structures and composite for the pharmaceutical training program at The University of Texas at El Paso (UTEP) and has been patented [22][23].

\section{MATERIALS AND HEAT TREATMENT}

All samples were printed as filaments having a $1.75 \times 10^{-3}$ $\mathrm{m}$ diameter using $3 \mathrm{D}$ printers designed by the research team, Center for Printable Materials Certification (CPMC), with a nozzle diameter of $8.0 \times 10^{-4} \mathrm{~m}$. The filaments used in this study were: PC-Plus from
Polymaker with a recommended printing temperature (RPT) of $250-270{ }^{\circ} \mathrm{C}$; PMMA from Rigid Ink, with a RPT of $250-260{ }^{\circ} \mathrm{C}$; and PEEK Filament from Victrex with a RPT of $360{ }^{\circ} \mathrm{C}$. Tensile and bending test samples were printed according to ASTM DS 638 standard type V, and ASTM 790 (see Figure 1), and tested in Test Resources 100 series equipment. Friction coefficient was measured on discs with a diameter of $4.5 \times 10^{-2} \mathrm{~m}$, using an Anton Paar TBR tribometer, with a $6.0 \times 10^{-3} \mathrm{~m}$ ball, a $5 \mathrm{~N}$ load, $30 \mathrm{rpm}$, and for 20 minutes. All tests were performed at room temperature $\approx 20{ }^{\circ} \mathrm{C}$.

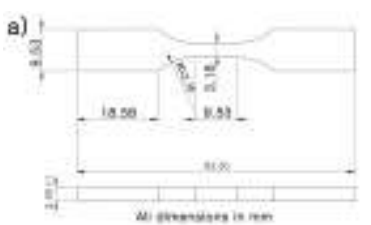

c)

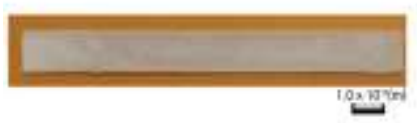

b)



d)

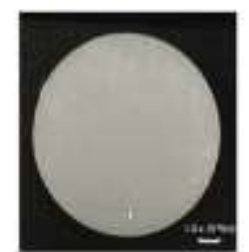

Figure 1. (a) Tensile Testing Standard Specimen specifications for ASTM DS 638 type V, (b) 3D printed sample used for tensile testing, (c) ASTM 790 bending test sample (d) pin-on wheel wear test sample.

Table 1 shows the printing temperature and heat treatment temperatures, for which 90 and $150 \%$ of the glass transition temperatures $\left(\mathrm{T}_{\mathrm{g}}\right)$ reported in the MSDS sheet from the suppliers. The samples were kept in the furnace for 60 minutes; then the furnace was turned off until room temperature was reached (around 60 minutes). For the bending and wear tests, the optimum printing and heat treatment temperatures were chosen.

Table 1. Printing temperatures and heat treatment temperatures used for PC, PMMA, and PEEK.

\begin{tabular}{|l|l|l|}
\hline Materials & Printing Temp. & $\begin{array}{l}\text { Post-Heat Treatment } \\
\text { Temp. }\end{array}$ \\
\hline PC & $232{ }^{\circ} \mathrm{C}, 255^{\circ} \mathrm{C}, 280{ }^{\circ} \mathrm{C}$ & $132{ }^{\circ} \mathrm{C}, 220{ }^{\circ} \mathrm{C}$ \\
\hline PMMA & $232{ }^{\circ} \mathrm{C}, 255^{\circ} \mathrm{C}, 280{ }^{\circ} \mathrm{C}$ & $97{ }^{\circ} \mathrm{C}, 162{ }^{\circ} \mathrm{C}$ \\
\hline PEEK & $345{ }^{\circ} \mathrm{C}, 355^{\circ} \mathrm{C}$ & $128{ }^{\circ} \mathrm{C}, 215{ }^{\circ} \mathrm{C}$ \\
\hline
\end{tabular}

\section{RESULTS AND DISCUSSION}

Shore Hardness values were obtained from the 3D printed samples before and after heat treatment. The hardness of the printed samples increased after heat treatment, but it mainly decreased when the annealing temperature was at $150 \%$ of $\mathrm{T}_{\mathrm{g}}$.

The tensile strength values for PC, PMMA, and PEEK are 65, 70, and $96 \mathrm{MPa}$ respectively as seen in Figure 2. And also, it shows the tensile results before and after heat treatment. Heat treatment of PC at $90 \%$ of Tg resulted in an increase in the strength of around $10 \mathrm{MPa}$ at all printing temperatures. The heat treatment at $150 \%$ of $\mathrm{Tg}$ 
made the samples to become very brittle, showing a sharp decrease in UTS around $80 \mathrm{MPa}$ to about $40 \mathrm{MPa}$ after the heat treatment.

For PMMA, the results also showed a slight increase in strength for the heat treatment at $90 \%$ of $\mathrm{T}_{\mathrm{g}}$, from about 60 to $80 \mathrm{MPa}$, and a sharp decrease of strength and ductility when heat treated at $150 \%$ of $\mathrm{T}_{\mathrm{g}}$. Both $\mathrm{PC}$ and PMMA showed a reduction in Young's modulus when heat treated at $150 \%$ of $\mathrm{T}_{\mathrm{g}}$, as can be observed by the decrease in the slope in all cases. PEEK demonstrated a minimal change in stress after heat treatment.

As heat treatment was increased to $150 \%$ of $\mathrm{T}_{\mathrm{g}}$, the change in Young's modulus was minimum, although the UTS showed a decrease.

\section{TENSILE TESTS}
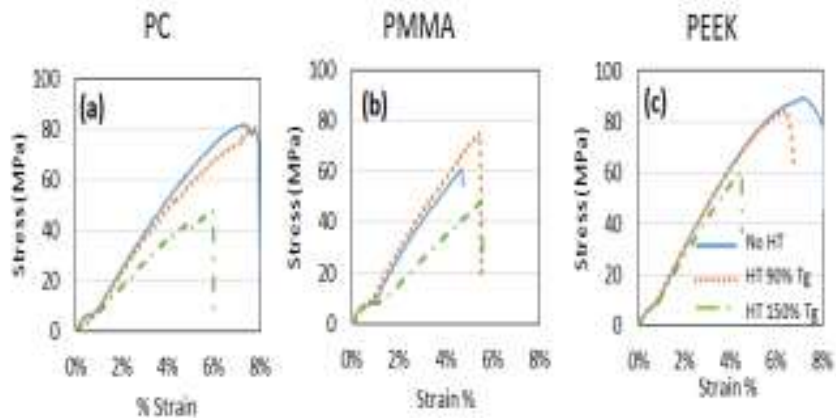

Figure 2. Tensile test results of (a) PC, (b) PMMA and (c) PEEK before and after heat treatment.

Heat treatments at $150 \%$ of $\mathrm{T}_{\mathrm{g}}$, resulted in deformation and change in sample size dimensions. For this reason, it was decided to conduct the bending and wear testing for heat treatments only at $90 \%$ of $\mathrm{T}_{\mathrm{g}}$.

Bending tests results are depicted in Figure 3(a) PC, (b) PMMA and (c) PEEK. These tests did not show much improvement in the strength of any of the tested polymers. There was a change in the maximum load of less than $10 \%$, in all three polymers. The most significant difference between them is the fact that PMMA showed a more brittle behavior, but results were very similar to the ones obtained in tensile tests, while PC and PEEK exhibited distinct behaviors by tensile and bending test. Previous studies have also suggested the results of tensile and bending varies with the size of the specimen, as well as the strain rate. The results indicated that it would be essential to test depending on the future applications of the material.

\section{BENDING TESTS}
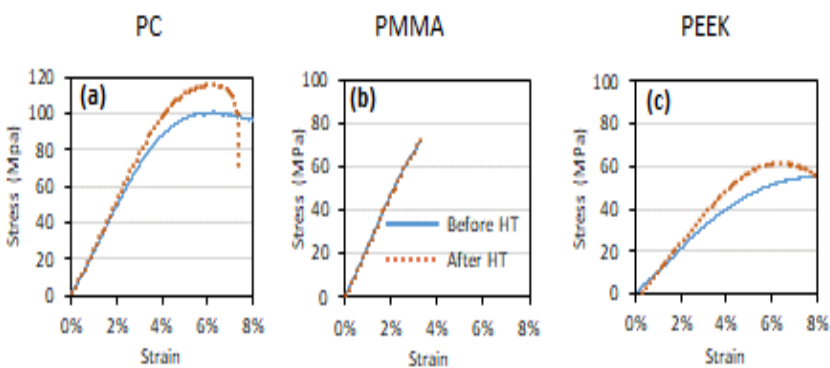

Figure 3. Bending test results of (a) PC, (b) PMMA and (c) PEEK before and after heat treatment.

Wear testing was performed on circular samples measuring $4.0 \times 10^{-2} \mathrm{~m}$ in diameter. Figure 4 shows the mean Friction Coefficient values, inset in the graph depicts SEM image of wear test zone showing the worn line.

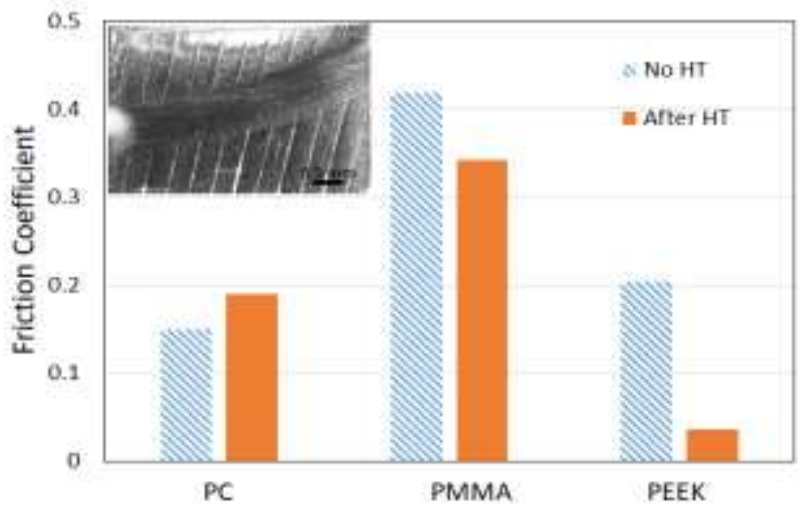

Figure 4. Mean Friction Coefficient values obtained for circular samples of the three polymers used. Inset showing SEM representative image of wear test area on a PMMA sample without heat treatment

For the further application of PMMA and its tribological behavior, wear test was implemented as shown in Figure 5. It was tested as constant the normal force of the pin (5 $\mathrm{N})$, the pin diameter $\left(6.0 \times 10^{-3} \mathrm{~m}\right)$, the wear radius track $\left(1.0 \times 10^{-2} \mathrm{~m}\right)$, the time that the test took place $(20$ minutes), and the rotation velocity of the disk (30 rpm). Based on the results obtained, Figure 5 also shows a slight decrease in the friction coefficient after heat treatment, which suggests that the surface obtained after heat treatment is more smother in comparison to the one obtained before heat treatment. These results demonstrate that roughness obtained during the $3 \mathrm{D}$ printing process was bigger if heat treatment is not performed, which is favorable for the biocompatibility.

Although it is shown that the mechanical properties increased after heat treatment (Figs. 2 and 3), it is important to mention that the roughness of the $3 \mathrm{D}$ printed piece decreased which cannot be favorable for the initial cell survival rate and cell attachment, which can lead to a rejection of the piece by the body. The SEM images 
(Figure 5), shows the road formed by the wear test, before ( $a$ and $b$ ) and after ( $c$ and d) heat treatment.
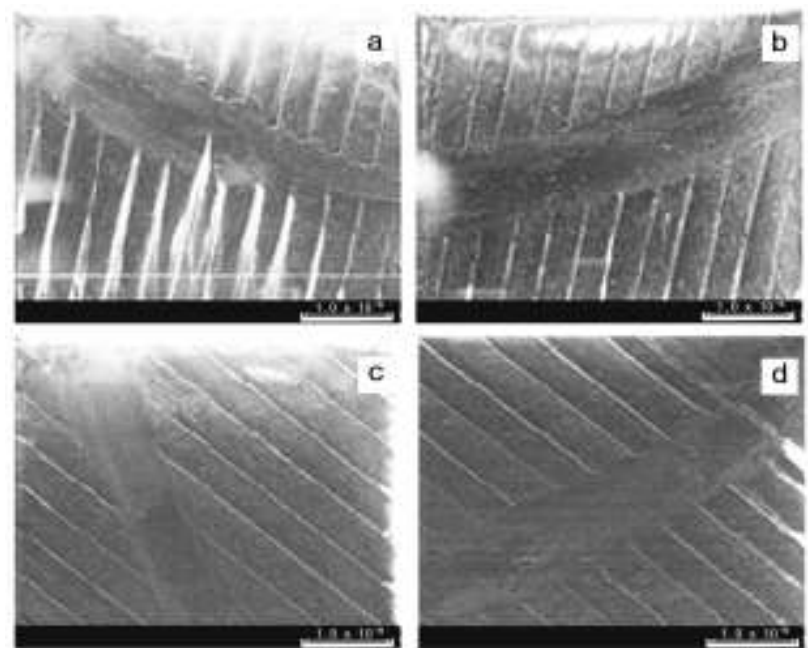

Figure 5 SEM images of the 3D printed PMMA disc after the wear test. (a) \& (b) before Heat Treatment, (c) \& (d) after Heat Treatment

The SEM images Figure $5 \mathrm{a}$ ) and b) shows an irregular and deeper road compared to that of in the c) and d) images. Also, the SEM images in Figure $5 \mathrm{c}$ ) and d) show a smoother surface compared to the that in Figure 5 a) and b) images. The comparison shows how the heat treatment influenced the surface properties and the abrasion resistance of the $3 \mathrm{D}$ printed material.

Figure 6 shows the relation between the friction coefficient versus time for PMMA samples. In the beginning, a constant and rapid increment of static friction with a slope of 0.0092 is shown with a duration of nearly 100 seconds.

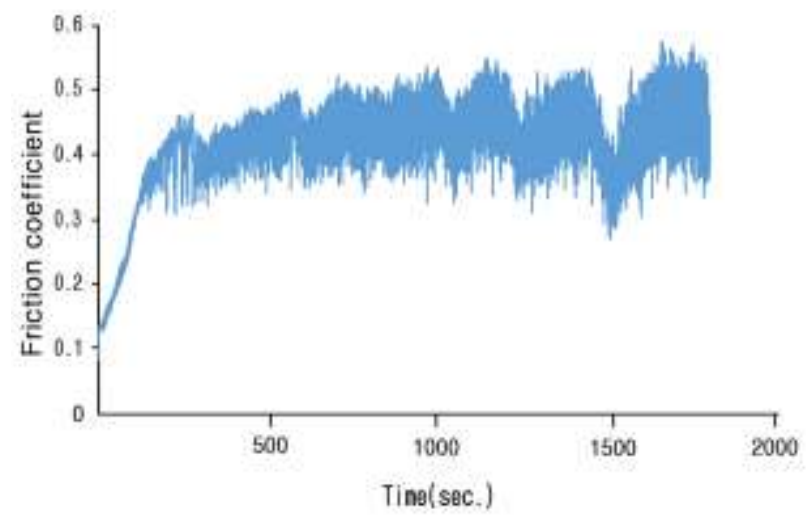

Figure 6 Wear test before heat treatment for PMMA

Figure 7 (sample after heat treatment) shows a slow increment compared to the sample before heat treatment with a slope of 0.0015 and a duration of nearly 700 seconds

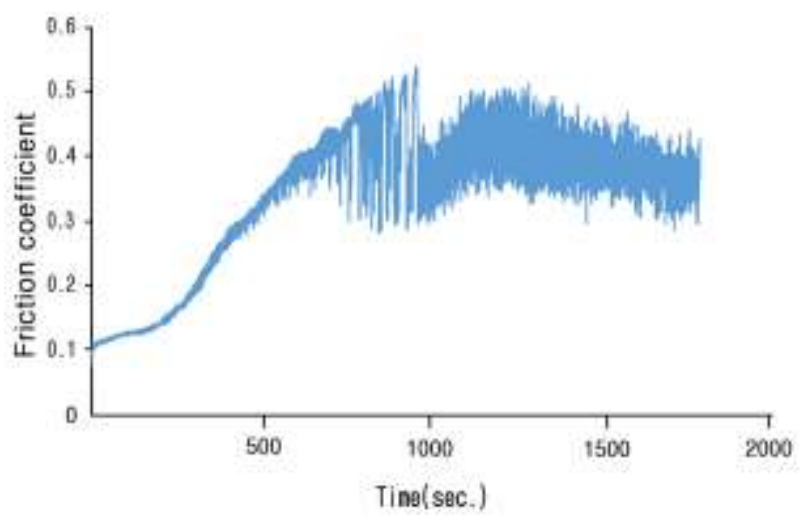

Figure 7. Wear test After Heat Treatment for PMMA

The force required to remove material during the test is less after- than before- heat treatment, which supports the hypothesis that the roughness after heat treatment decreases. The roughness of the surface and the porosity of the sample can lead to the optimal biocompatibility of the cells and a rapid recovery process from the surgery. The effect that roughness has on the surface made by the $3 \mathrm{D}$ printing process can be observed in Figure 8. The surface roughness data was obtained from point a to point $\mathrm{b}$ in Figure 8 and which is 1.47 , where 1 represent a smoother surface and more than one represents a rough surface.

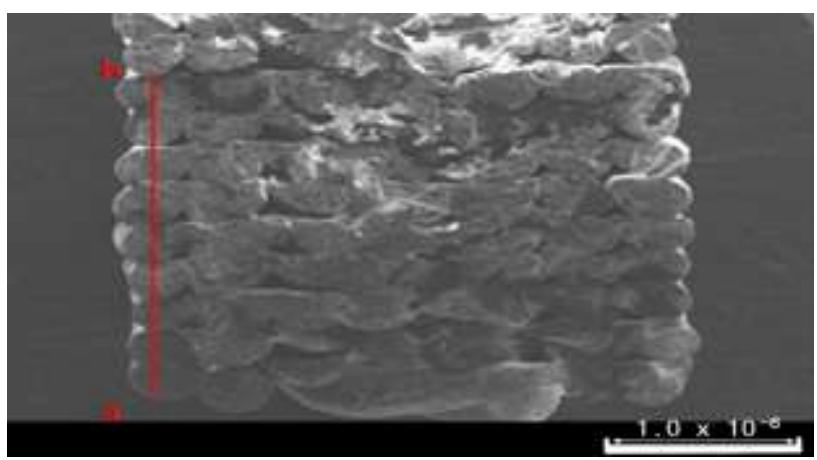

Figure 8 SEM image of the cross-sectional area of PMMA Tensile Testing Standard "ASTM DS 638 type V"

\section{CONCLUSIONS}

An increase in strength was observed in the polymers used after heat treatment than 3D Printed as-is (before). The increase in strength was due to the recrystallization that the materials undergo during heat treatment. The 3D printing technique deposits fused filament layer by layer, as it solidifies, it undergoes recrystallization in which the molecules are rearranged in an ordered position. However, it is critical not to exceed the $\mathrm{Tg}$ temperature of the materials for heat treatment because it results in a decrease in strength. Even though PEEK did not show a change in dimensions as large as the other polymers; PC and PMMA, no benefits were observed in subjecting the polymers to a heat treatment above their $T_{g}$

\section{ACKNOWLEDGEMENTS}


This study was supported by UTEP-SKU Program: 226-900233A "Master Program Using Drug Delivery System (DDS) for Pharmacy Training"

\section{REFERENCES}

1. J Hoffman, S Hwang, A Ortega, NS Kim, K Moon., The standardization of printable materials and direct writing systems, Journal of Electronic Packaging 135 (1), 01106 (2013)

2. ASTM D638-14 Standard Test Method for Tensile Properties of Plastics, ASTM International, West Conshohocken, PA (2014), https://doi.org/10.1520/D0638-14.

3. A. A. Aly, Heat Treatment of Polymers: A Review, Int. J. Mater. Chem. Phys, 1 (2), 132140, (2015)

4. ASTM D790 Standard Test Methods for Flexural Properties of Unreinforced and Reinforced Plastics and Electrical Insulating Materials. [Online]. Available: https://compass.astm.org/EDIT/html_annot.cgi? D790+17. [Accessed: 18-Apr-2018].

5. F. P. Bowden and Tabor D., Friction and lubrication in solids (1964).

6. K. Tanaka, Kinetic friction and dynamic elastic contact behavior of polymers (1984).

7. C. Weckle, Polycarbonate Remains Proven and Preferred for Medical Applications, (Tech Briefs :: Medical Desi Medicine, Second Edi. 2011. gn Briefs., MEdical Design Briefs, (2013. [Online]. Available: https://www.medicaldesignbriefs.com/compone $\mathrm{nt} /$ content/article/mdb/features/17693.

[Accessed: 31-Jan-2018].

8. D. G. Powell., Medical Applications of Polycarbonate (MDDI Online, Medical Device and Diagnostic Ind., (1998). [Online]. Available: https://www.mddionline.com/medical-

applications-polycarbonate. [Accessed: 31-Jan2018].

9. K. J. Mark HF, Bikales NM, Overberger CG, Menges G., PEEK Biomaterials in Trauma, Orthopedic, and Spinal Implants. 313-320 (1988).

10. S. M. Kurtz and J. N. Devine, PEEK biomaterials in trauma, orthopedic, and spinal implants (Biomaterials, 28 (32), 4845-69 (2007).

11. J. Black, Biological performance of materials: fundamentals of biocompatibility CRC Taylor \& Francis (2005).

12. J. Black. G. Hastings. Handbook of biomaterials properties (1998).

13. KN Han, NS Kim., Challenges and opportunities in direct write technology using nano-metal particles, KONA Powder and Particle Journal, 27, 73-83 (2009)

14. AK Amert, DH Oh, NS Kim., A simulation and experimental study on packing of nanoinks to attain better conductivity (Journal of Applied Physics, 108 (10) 2010)
15. S Hong, N Kim., Synthesis of 3D Printable $\mathrm{Cu}-$ Ag Core-Shell Materials: Kinetics of $\mathrm{CuO}$ Film Removal (Journal of Electronic Materials, 44 (3), 823-830 (2015)

16. S.E Najera, M. Michel, and N.Kim.,3D Printed PLA/PCL/TiO2Composite for Bone Replacement and Grafting, MRS Advances, 3 (40), 2373-2378 (2018)

17. S. Ramakrishna, J. Mayer, E. Wintermantel, and K. W. Leong., Biomedical applications of polymer-composite materials: a review, Compos. Sci. Technol, 61 (9), 1189-1224 (2001).

18. J. R. C. Dizon, A. H. Espera, Q. Chen, and R. C. Advincula., Mechanical characterization of 3Dprinted polymers, ddit. Manuf, 20, 44-67 (2018)

19. NS Kim, KH Han, KH Church., Direct Writing Technology for 21st Century Industries-Focus on Micro-Dispensing Deposition Write Technology, Transactions of the KSMTE Spring Conference 511-515 (2007)

20. Kim, N.S., Eo, J.S., \& Cho, D. Optimization of Piston Type Extrusion (PTE) Techniques for 3D Printed Food. Journal of Food Engineering, 235(10), 41-49 (2018).

21. KL Mendoza, A Ortega, NS Kim, Optimization of UV LED-Curable Ink for Reverse-Offset Roll-to-Plate (RO-R2P) Printing, J. of Elect. Mat. 44 (3), 784-791 (2015)

22. J. Eo, B. Cepeda, J. Kim, and NP Kim, A New Paradigm of Pharmaceutical Drug Delivery Systems (DDS): Challenges for Space, Time, and Shapes, Innovations in pharmacy, 9(3), 1124 (2018)

23. Kim, N., Eo, J., \&Shin, J., Three-Dimensional Printed Drug Delivery System and Method, US Patent 62/745139 (2018) 